\title{
The Effect of Characteristics of Wearing an Assistive Listening Device on Literacy for School-age Hearing-impaired Children
}

\author{
Sung-Yong Ryu1), Soon-Gil Park2)
}

\begin{abstract}
This study examined whether literacy in hearing impaired children differs depending on their characteristics related to the use of assistive listening devices. To this end, we selected the groups with matching chronological age, raven scores, and language age. A total of 20 children wearing hearing aids and 20 further children with cochlear implants participated in the study. The participants were first or second-graders in elementary schools and attended language therapy rooms. As study tools, the Korea-standard progressive matrices, the receptive \& expressive vocabulary test, the Korea test of literacy diagnosis in Korean, and the diagnostic test of basic learning were used. The results were as follows. First, children with cochlear implants performed better than those wearing hearing aids on the word recognition and fluency tasks. In addition, the longer was the wearing period of hearing aids, the better was the performance of literacy. However, no significant differences were observed between two groups according to their wearing time. Second, there were correlations between the characteristics of the assistive listening devices of hearing-impaired children and their literacy, kinds of hearing aids, discovery time of hearing loss, and wearing periods. Therefore, the results of this study suggest that early detection of hearing impairment and early use of assistive listening devices according to the characteristics of hearing loss is necessary to improve the literacy of hearing-impaired children.
\end{abstract}

Keywords: Cochlear Implants, Hearing Aids, Hearing Impairment, Reading, Writing

\section{Introduction}

\subsection{Purpose of the Study}

All human beings communicate with each other by using various channels of communication. However, unlike auditory children who are naturally exposed to language environment since they are born, hearing-impaired children's communication is limited even in terms of hearing, which is the first step of language acquisition. Hearing-impaired children's delayed language

Received(April 9, 2020), Review Result(1st: May 26, 2020, 2nd: July 7, 2020), Accepted(July 27, 2020)

1) (Student) 57344 Dept. Damyang Language Learning Center., 7-29 Gijo-gil, Damyang-eup, Damyang-gun, Jeollanam-do, Korea

email: rc7440@hanmail.net

2) (Professor, Corresponding Author) 62271 Dept. Elementary Special Education, Nambu Univ., 23 Chumdan Jungang-ro, Gwangsan-gu, Gwangju, Korea

email: psoongil@nambu.ac.kr 


\section{The Effect of Characteristics of Wearing an Assistive Listening Device on Literacy for School-age Hearing-impaired Children}

development that is linked to the difficulty in listening disturbs their reading and understanding of letters, as well as curbs their ability to express their thoughts in writing as they start school[1].

Literacy usually means the ability to read and write in letters[2]. Reading can be divided into word recognition, comprehension, and fluency[3]. Word recognition is the process in which visually presented letters are matched with sounds, comprehension is an ability to understand contexts presented with letters, and fluency is an ability to easily and naturally read them. In addition, writing is the ability to arrange phonemes based on language knowledge[4].

Hearing-impaired children show a variety of linguistic characteristics in the degree, time, and areas of hearing loss. In order to alleviate the difficulty in listening caused by hearing loss, they use assistive listening devices, such as hearing aids and cochlear implants[5]. Among them, hearing aids transfer external sound to the hearing organs by amplifying them, furthermore, cochlear implants, electric devices replacing the function of hair cells, by converting external sounds into electric signals and directly transferring them to the auditory nerve. These devices make a significant contribution to the education and rehabilitation for hearing-impaired persons[6]. Previous studies reported differences in the literacy according to the kinds of assistive listening devices, suggesting that literacy of children with cochlear implants is higher than that of those wearing hearing aids[7].

The earlier is the discovery time of hearing loss and the wearing time of assistive listening devices, the better is the development of language and literacy[8]. It has been emphasized that, in terms of the linguistic development, the discovery time of hearing loss is more important than its degree[9]. For instance, [10] reported that wearing assistive listening devices before 24 months of age enhanced children's language skills.

The longer are the wearing periods of assistive listening devices, the better are the language skills and literacy. It was reported that speech perception and the production of voices were stabilized two years after the first wearing of such devices, and that longer wearing periods and better threshold after wearing have positive effects on the development of language and literacy[8].

As discussed above, hearing-impaired children experience difficulties in acquiring literacy due to the difficulty in listening. Overall, previous studies on literacy in children with hearing impairments have been limited in Korea. If hearing-impaired children who have difficulty in listening can complement their hearing by using assistive listening devices, not only the development of language, but also the literacy would be affected, which are also expected to vary depending on characteristics of wearing an assistive listening device such as discovery 
time of hearing loss, wearing time, and wearing periods. This study thus attempts to examine the changes in literacy according to the discovery time of hearing loss, wearing time, and wearing periods.

\subsection{Research Question}

This study aims to investigate hearing-impaired children's reading (word recognition, fluency, and comprehension) and writing characteristics according to their characteristics of assistive listening device use(kinds of hearing aids, discovery time of hearing loss, wearing time, and wearing periods).

Hence, the two research questions addressed in the present study are as follows.

First, How does hearing-impaired children's literacy vary depending on their characteristics of wearing an assistive listening device?

Second, Does hearing-impaired children's literacy correlate with their characteristics of wearing an assistive listening device?

\section{Methods}

\subsection{Participants}

The study participants included 20 children wearing hearing aids and further 20 children with cochlear implants. All participants lived in Gyeonggi-do, Gwangju, Daejeon, Seoul, Jeonnam and Jeonbuk and attended language therapy rooms.

The inclusion criteria to select hearing-impaired children were as follows. (1) enrollment in the first to the second grade in an elementary school, (2) hearing loss before two years of age, (3) wearing assistive listening devices before three years of age, (4) no other multiple disabilities except for hearing disabilities, (5) no serious deformation of internal ears, (6) use of spoken language as the communication channel, (7) hearing loss of both ears, higher than $70 \mathrm{~dB}$, before wearing assistive listening devices, (8) wearing the same kind of assistive listening devices for both ears, (9) parents holding high school degrees or higher. The chronological age, raven scores, and language age of the participants are summarized in [Table 1].

As shown in [Table 1], the average chronological age of some children wearing hearing aids and others with cochlear implants was 95.27 months old and 97.33 months old, respectively. In addition, each group consisted of children with homogeneous raven scores and language age. 
The Effect of Characteristics of Wearing an Assistive Listening Device on Literacy for School-age Hearing-impaired Children

[Table 1] Participants' Chronological Age, Raven Scores, and Language Age

\begin{tabular}{ccccccc}
\hline \multirow{2}{*}{ Sortation } & \multicolumn{2}{c}{$\begin{array}{c}\text { Children wearing hearing aids } \\
(\mathrm{n}=20)\end{array}$} & \multicolumn{2}{c}{$\begin{array}{c}\text { Children with cochlear } \\
\text { implants }(\mathrm{n}=20)\end{array}$} & \multirow{2}{*}{$\mathrm{t}(\mathrm{p})$} \\
\cline { 2 - 6 } & $\mathrm{M}$ & $\mathrm{SD}$ & $\mathrm{M}$ & $\mathrm{SD}$ & \\
\hline \multicolumn{2}{c}{ Age } & 95.27 & 6.36 & 97.33 & 8.55 & $.02(.882)$ \\
\hline \multicolumn{2}{c}{\begin{tabular}{c} 
Raven \\
\multirow{2}{*}{$\begin{array}{c}\text { Language } \\
\text { Age }\end{array}$}
\end{tabular}} & 31.55 & 3.01 & 30.38 & 2.74 & $-.17(.863)$ \\
\cline { 2 - 6 } & Receptive & 101.55 & 2.77 & 104.88 & 4.87 & $1.29(.229)$ \\
\hline
\end{tabular}

\subsection{Tools}

\subsubsection{Raven Test}

In order to secure the homogeneity of both groups, K-SPM[11] was conducted. K-SPM consists of a total of 60 items, with 12 items in the following 5 sets. A, B, C, D and E. The first and second-graders undergo $A$ to $D$, while third-graders undergo $A$ to $E$. To ensure the homogeneity of first and second graders, we used a total of 48 items from A, B, C and D. In this study, Cronbach's a was .76.

\subsubsection{Receptive \& Expressive Vocabulary Test}

REVT[12] was also performed out to secure the homogeneity of some children wearing hearing aids and others with cochlear implants. The order of the test was as follows. The expressive vocabulary test was first conducted, and then the receptive vocabulary test started with the baseline of the expressive vocabulary test. Then, raw scores were calculated and used to determine the language age of both receptive and expressive language. In this study, each Cronbach's a values of receptive and expressive vocabulary tests were .91 and .94 , respectively.

\subsubsection{The Korea Test of Literacy Diagnosis}

To examine word recognition, fluency, and writing of both groups, K-TOPD[13] was used.

In order to measure word recognition, type A word reading test, a sub-test of K-TOLD, was conducted. The word reading test consists of a total of 96 items. It presents a letter plate to children and gives 1 , if they can correctly read it and 0 , if they cannot, and the test would be stopped, if they continued to read five items incorrectly. This study measured reading skills of the participants by calculating raw scores, with Cronbach's a of .92 .

In order to measure fluency, the type A word reading fluency test, a sub-test of K-TOLD, was carried out. This test consists of a total of 98 syllables in 49 words consisting of two 
syllables, and the total scores were calculated by measuring the number of syllables the participants could quickly and correctly read. This study measured the fluency abilities by using raw scores, with Cronbach's a of .90 .

\subsubsection{Basic Learning Skills Test}

To examine comprehension, we conducted Reading II, a sub-test of the basic learning skills test[14]. This test asks children to read some sentences and select paintings that match the meanings of the sentences. The test consists of 50 items and gives 1 each for correct responses and 0 each for incorrect ones and would be stopped if the children's responses to five items are continuously incorrect. This study measured children's reading comprehension by using raw scores, with Cronbach's a of .91 .

\subsection{Procedure}

The data were collected from December 2018 to March 2019. All tests were conducted through prior consultation with children's caregivers. The tests were carried out in a quiet space the children were familiar with, without any interruptions. Both the order and method of the test were adequately explained, and then, the main test was conducted after an exercise. The test was conducted for about 2-3 hours and was divided into two or three sessions, depending on the children's test performance and concentration. A 10-minute break between the tests was provided.

\subsection{Data Analysis}

The data were analyzed using SPSS 20.0. First, we performed a descriptive statistical analysis of the frequency of characteristics of assistive listening device use of both groups of children. T-test to ensure the homogeneity of both groups was also conducted. To investigate the reliability of raven, vocabulary, reading(word recognition, fluency, comprehension) and writing, we also estimated Cronbach's a. Second, the independent sample t-test was conducted to examine the literacy characteristics of children in the two groups. Third, a correlation analysis was performed to understand the correlation between characteristics of wearing an assistive listening device and literacy. 
The Effect of Characteristics of Wearing an Assistive Listening Device on Literacy for School-age Hearing-impaired Children

\section{Result}

\subsection{Characteristics of Hearing-impaired Children according to Their General Characteristics}

\section{1) Literacy between groups by kinds of assistive listening devices}

This study examined the differences in literacy(word recognition, fluency, comprehension, and writing) between both groups, and the results are summarized in [Table 2].

[Table 2] Characteristics of Literacy between by Kinds of Assistive Listening Devices

\begin{tabular}{llcccccc}
\hline \multirow{2}{*}{ Variable } & \multicolumn{2}{c}{$\begin{array}{c}\text { Children wearing hearing } \\
\text { aids }(\mathrm{n}=20)\end{array}$} & \multicolumn{2}{c}{$\begin{array}{c}\text { Children with cochlear } \\
\text { implants }(\mathrm{n}=20)\end{array}$} & $\mathrm{t}$ & $\mathrm{p}$ \\
\cline { 2 - 7 } & $\mathrm{M}$ & $\mathrm{SD}$ & $\mathrm{M}$ & $\mathrm{SD}$ & & \\
\hline \multirow{3}{*}{ Reading } & Word recognition & 51.27 & 3.69 & 54.72 & 5.19 & $2.29^{*}$ & .028 \\
\cline { 2 - 8 } & Fluency & 65.33 & 3.37 & 68.38 & 3.68 & $2.59^{*}$ & .014 \\
\cline { 2 - 8 } & Comprehension & 13.55 & 4.47 & 16.33 & 5.00 & 1.75 & .088 \\
\hline Writing & 7.83 & 2.28 & 9.00 & 2.32 & 1.51 & .138 \\
\hline${ }^{*} \mathrm{p}<.05$ & & & & & & &
\end{tabular}

As shown in [Table 2], we examined the differences in literacy by dividing assistive listening devices into hearing aids and cochlear implants. The results showed that there were significant differences in word recognition $(t=2.29, p<.05)$ and fluency $(t=2.59, p<.05)$. In other words, children wearing hearing aids $(\mathrm{M}=21.27)$ had lower scores of work recognition than did those with cochlear implants( $M=54.72)$, the former( $M=65.33)$, furthermore, the former group also had lower scores of fluency than the latter $(\mathrm{M}=68.38)$. However, no significant differences in comprehension $(t=1.90, p>.05)$ and writing $(t=1.85, p>.05)$ between two groups were observed. Hence, it can be concluded that the former group's word recognition and fluency were poorer than those of the latter group.

\section{2) Literacy between Groups by Discovery Time of Hearing Loss}

The differences in literacy(word recognition, fluency, comprehension, and writing) by the discovery time of hearing loss were examined. The results are reported in [Table 3].

As shown in [Table 3], the analysis of the differences in literacy between the two groups by the discovery time of hearing loss showed that there were significant differences between the groups before and after seven months old $(t=-2.55, \mathrm{p}>.05)$. Specifically, the scores of word 
recognition before seven months old $(\mathrm{M}=51.00)$ were higher than those after seven months old $(\mathrm{M}=54.78)$. There were, however, no significant differences in fluency, comprehension, and writing between the groups, regardless of the discovery time of hearing loss.

[Table 3] Characteristics of Literacy between the Groups by Discovery Time of Hearing Loss

\begin{tabular}{|c|c|c|c|c|c|c|c|}
\hline & \multirow{2}{*}{ Variable } & \multicolumn{2}{|c|}{ Before 7 months $(n=19)$} & \multicolumn{2}{|c|}{ After 7 months $(n=21)$} & \multirow{2}{*}{$t$} & \multirow{2}{*}{$p$} \\
\hline & & $\mathrm{M}$ & SD & $\mathrm{M}$ & $\mathrm{SD}$ & & \\
\hline \multirow{3}{*}{ Reading } & Word recognition & 51.00 & 4.09 & 54.78 & 4.72 & $-2.55^{*}$ & .015 \\
\hline & Fluency & 65.58 & 3.55 & 68.00 & 3.75 & -1.97 & .057 \\
\hline & Comprehension & 13.52 & 4.67 & 16.21 & 4.83 & -1.68 & .101 \\
\hline writing & & 7.88 & 2.31 & 8.89 & 2.33 & -1.30 & .201 \\
\hline
\end{tabular}
${ }^{*} \mathrm{p}<.05$

\section{3) Characteristics of Literacy between Groups by Wearing Time of Assistive Listening} Devices

The differences in literacy(word recognition, fluency, comprehension, and writing) by the wearing time of assistive listening devices were examined. The results are reported in [Table 4].

[Table 4] Characteristics of Literacy between by Wearing Time of Assistive Listening Devices

\begin{tabular}{llcccccc}
\hline \multirow{2}{*}{ Variable } & \multicolumn{2}{c}{ Before 24 months $(n=24)$} & \multicolumn{2}{c}{ After 24 months $(n=16)$} & \multirow{2}{*}{$t$} & \multirow{2}{*}{$p$} \\
\cline { 2 - 7 } & & $M$ & $S D$ & $M$ & $S D$ & & \\
\hline \multirow{3}{*}{ Reading } & Word recognition & 52.95 & 4.25 & 53.07 & 5.66 & -.07 & .944 \\
\cline { 2 - 8 } & Fluency & 57.31 & 3.59 & 66.14 & 4.16 & .90 & .375 \\
\cline { 2 - 8 } & Comprehension & 14.59 & 4.74 & 15.50 & 5.22 & -.53 & .594 \\
\hline \multirow{2}{*}{ writing } & & 8.31 & 2.27 & 8.57 & 2.53 & -.31 & .757 \\
\hline
\end{tabular}

As shown in [Table 4], the differences in literacy of both groups by the wearing time of assistive listening devices were examined by dividing it into before 24 months old and after 24 months old. The findings showed that there were no significant differences in word recognition $(t=-.07, p>.05)$, fluency $(t=-.90, p>.05)$, comprehension $(t=-.53, p>.05)$ and writing $(t=-.31, p>.05)$.

\section{4) Characteristics of Literacy between Groups by Wearing Periods of Assistive Listening Devices}

The differences in literacy(word recognition, fluency, comprehension and writing) by the wearing periods of assistive listening devices were examined. The results are shown in [Table 5]. 
The Effect of Characteristics of Wearing an Assistive Listening Device on Literacy for School-age Hearing-impaired Children

[Table 5] Characteristics of Literacy between by Wearing Periods of Assistive Listening Devices

\begin{tabular}{|c|c|c|c|c|c|c|c|}
\hline & \multirow{2}{*}{ Variable } & \multicolumn{2}{|c|}{ Less than 72 months $(n F 21)$} & \multicolumn{2}{|c|}{ More than 72 months $(n F 19)$} & \multirow{2}{*}{$t$} & \multirow{2}{*}{$p$} \\
\hline & & $M$ & $S D$ & $M$ & $S D$ & & \\
\hline \multirow{3}{*}{ Reading } & Word recognition & 50.77 & 4.13 & 55.22 & 4.39 & $-3.12 * *$ & .004 \\
\hline & Fluency & 64.16 & 2.99 & 69.55 & 2.35 & $-5.99^{* * *}$ & .000 \\
\hline & Comprehension & 11.77 & 3.37 & 18.11 & 4.07 & $-5.08^{* * *}$ & .000 \\
\hline writing & & 7.00 & 1.84 & 9.83 & 1.91 & $-4.51^{* * *}$ & .000 \\
\hline
\end{tabular}

As shown in [Table 5], the differences in the literacy of children were examined by dividing them into some with the wearing periods of assistive listening devices less than 72 months and others with those over 72 months. The results showed that there were significant differences in word recognition $(t=-3.12, p>.01)$, fluency $(t=-5.99, p>.001)$, comprehension $(t=-5.08, p>.001)$, and writing ( $t=-4.51, p>$.001) between two groups. Hence, the longer are the wearing periods of assistive listening devices, the better is the performance of word recognition, fluency, comprehension, and writing.

\subsection{Correlation between the characteristics of assistive listening device use and Literacy}

The correlations between hearing-impaired children's characteristics of assistive listening device use and their literacy children are summarized in [Table 6].

[Table 6] Correlation between characteristics of wearing an assistive listening device and Literacy $\quad(n=40)$

\begin{tabular}{ccccccccc}
\hline variable & 1 & 2 & 3 & 4 & 5 & 6 & 7 & 8 \\
\hline 2 & -.05 & & & & & & & \\
\hline 3 & .11 & $.43^{* *}$ & & & & & & \\
\hline 4 & -.11 & -.05 & -.19 & & & & \\
\hline 5 & $-.36^{*}$ & $.40^{*}$ & .09 & $.47^{* * *}$ & & & \\
\hline 6 & -.40 & .32 & .08 & $.71^{* * *}$ & $.78^{* * *}$ & & \\
\hline 7 & -.28 & .27 & .26 & $.65^{* * *}$ & $.80^{* * *}$ & $.86^{* * *}$ & \\
\hline 8 & -.25 & .21 & .20 & $.61^{* * *}$ & $.72^{* * *}$ & $.84^{* * *}$ & $.85^{* * *}$ \\
\hline
\end{tabular}

${ }^{*} \mathrm{p}<.05,{ }^{* *} \mathrm{p}<.01,{ }^{* * *} \mathrm{p}<.001$ Variables: $1=\mathrm{kinds}$ of assistive listening devices, $2=$ discovery time of hearing loss, $3=$ wearing time, $4=$ wearing periods, $5=$ =word recognition, $6=$ fluency, $7=$ Comprehension, $8=$ writing

As shown in [Table 6], the correlations between hearing-impaired children's characteristics of wearing an assistive listening device and their literacy showed that the word recognition had correlations with wearing periods of assistive listening devices(r=.47), discovery time of hearing $\operatorname{loss}(\mathrm{r}=.40)$, kinds of assistive listening devices $(\mathrm{r}=-.36)$, fluency correlated with wearing periods of assistive listening device $(\mathrm{r}=.71)$, comprehension correlated with wearing periods of assistive 
listening devices $(\mathrm{r}=.65)$, and writing correlated with wearing periods of assistive listening $\operatorname{devices}(\mathrm{r}=.61)$.

\section{Discussion and Conclusion}

This study examined the differences in hearing-impaired children's literacy according to their characteristics of wearing an assistive listening device, and the correlation among them.

First, regarding the differences in literacy by assistive listening devices, the results showed that children wearing hearing aids had a lower performance in word recognition and fluency than did those with cochlear implants. This result is consistent with that of previous studies [10] indicating that children's language skills were significantly improved by using cochlear implants. Children whose hearing loss was discovered before 7 months of age demonstrate a higher performance of word recognition than those whose hearing loss was discovered after 7 months of age, which is consistent with the result that the latter occurs the discovery time, the better are the children's language skills[8], however, this results does not agree with another finding that the earlier is the discovery, the better are the children's language skills[7]. This disparity could be explained by the criterion on which the discovery time of the participants was divided and individual characteristics. The result also coincides with that of previous studies finding that the longer was the wearing periods of assistive listening devices, the better was the performance of literacy[10]. However, no differences in literacy were observed between the groups according to wearing time. This result may contradict the previous study demonstrating that the earlier is the wearing time, the better is the development of literacy[8].

Second, variables correlating with the literacy of hearing-impaired children include kinds of assistive listening devices, discovery time of hearing loss, and wearing periods. These results may be consistent with that of previous studies on the linguistic development and literacy of hearing-impaired children[10].

For the follow-up study, the following suggestions are made.

First, we examined literacy according to the characteristics of wearing an assistive listening device of hearing-impaired children. however, in further research, it would be necessary to investigate the relationship with various variables, because other variables can affect literacy.

Second, the present research is a cross-sectional study on literacy of hearing-impaired children attending lower grades of elementary schools. Therefore, in order to better understand the correct development of literacy, it is necessary to conduct a longitudinal study considering general characteristics. 


\section{References}

[1] P. Paul, Reading vocabulary and deafness, Journal of Deaf Studies and Deaf Education, (1996), Vol.1, No.1, pp.3-15.

[2] S. G. Park, J. R. Cho, S. H. Park, Comparisons of Korean literacy and cognitive-linguistic skills among preschool children from rural and urban communities and multicultural families, Journal of Speech-Language \& Hearing Disorders, (2014), Vol.23, No.4, pp.33-46.

[3] C. S. Lee, The characteristics of decoding process in the reading of Korean scripts, Hangul and teaching method for fostering of learning to decode, International Journal of Early Childhood Education, (2003), Vol.23, No.1, pp.5-26.

[4] S. G. Park, G. H. Mun, Analysis of reading acquisition and writing morphologic errors of university students, Asia-Pacific Journal of Multimedia Services Convergent with Art, Humanities, and Sociology, (2016), Vol.6, No.8, pp.155-163.

[5] S. G. Park, S. Y. Ryu, Analysis on speech therapists' recognitions and demands on children with hearing impairment, Asia-Pacific Journal of Multimedia Services Convergent with Art, Humanities, and Sociology, (2016), Vol.6, No.9, pp.595-604.

[6] M. S. Lee, K. N. Choi, S. J. Jin, A study on phonological awareness and phonological memory characteristics in school-aged children with cochlear implants, The Korean Society of Education for Hearing-Language Impairments, (2018), Vol.9, No.2, pp.89-107.

[7] A. E. Geers, Predictors of reading skill development in children with early cochlear implantation, Ear and Hearing, (2003), Vol.24, No.1, pp.59-68.

[8] M. J. Huh, The effect of cochlear surgery period and wear period on language education for children with hearing impairment, The Korean Society of Special Education, (2014), Vol.6, No.1, pp.95-105.

[9] E. Shojaei, Z. Jafari, M. Gholami, Effect of early intervention on language development in hearing-impaired children, Iranian Journal of Otorhinolaryngology, (2016), Vol.28, No.84, pp.13-31.

[10] C. Gallego, M. T. Aragoneses, R. Lopez-Higes, G. Pisón, Semantic and syntactic reading comprehension strategies used by deaf children with early and late cochlear implantation, Research in Developmental Disabilities, (2016), Vol.49, No.1, pp.153-17.

[11] H. C. Lim, Korea-standard progressive matrices, Korea Seoul: Korea Guidance, (2004)

[12] Y. T. Kim, G. H. Hong, K, H, Kim, H. S. Chang, H. Y. Lee, Receptive \& expressive vocabulary, Korea Seoul: Seoul Community Rehabilitation Center, (2009)

[13] J. Y. Cho, Y. S. Kim, S. K. Park, The Korea Test of Literacy Diagnosis, Korea Seoul: Korea Guidance, (2017)

[14] K. S. Park, J. R. Yoon, H. J. Park, Individual Basic Learning Skills Test, Korea: Korean Educational Development Institute, (1989) 